\title{
Intercalation and adsorption of ciprofloxacin by layered chalcogenides and
}

\section{2 kinetics study}

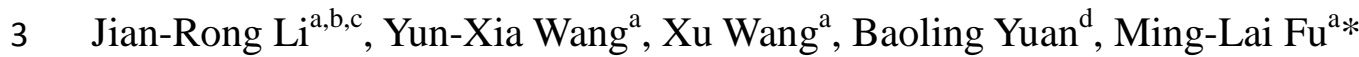

4 a. Key Laboratory of Urban Pollutant Conversion, Institute of Urban Environment, Chinese Academy of 5 Sciences, Xiamen, Fujian 361021, P.R. China.

6 b. Ningbo Urban Environment Observation and Research Station-NUEORS, Chinese Academy of Sciences,

$7 \quad$ Ningbo, Zhejiang 315800, P.R. China.

8 c. State Key Laboratory of Structural Chemistry, Fujian Institute of Research on the Structure of Matter, Chinese 9 Academy of Sciences, Fuzhou, Fujian 350002, P.R. China

*Corresponding author: Tel.: +865926190762; Fax: +865926190977; E-mail address: mlfu@iue.ac.cn 
13 Abstract: The hydrothermally synthesized layered chalcogenide, $\mathrm{K}_{2 \mathrm{x}} \mathrm{Mn}_{\mathrm{x}} \mathrm{Sn}_{3-\mathrm{x}} \mathrm{S}_{6}(\mathrm{x}=0.5-0.95)$ (KMS-1), was applied to remove ciprofloxacin from aqueous solution. Kinetic data showed the removal reaction followed a pseudo-second-order kinetic model and the rate controlling step was both through external film and intraparticle diffusion. The adsorption of CIP by KMS-1 is endothermic and the maximum adsorption capacity of KMS-1 was $199.6,230.9$ and $269.5 \mathrm{mg} / \mathrm{g}$ at temperature of 10,25 and $40{ }^{\circ} \mathrm{C}$, respectively. The heavy metal ions had great effect on the removal efficiency of CIP and the degree of inhibition followed the order: $\mathrm{Pb}^{2+}>\mathrm{Zn}^{2+}>\mathrm{Cd}^{2+}>\mathrm{Ni}^{2+}$. The shift of Bragg peaks from XRD at various $\mathrm{pH}$ accompanying CIP removal and FE-SEM images confirmed that cation exchange is the major mechanism for the adsorption of CIP by KMS-1. In the $\mathrm{pH}$ range of 4.0-7.0, the intercalation of cationic CIP adopted a titled orientation of di-molecular CIP in KMS-1 with the titling angle of $68^{\circ}$ and $42^{\circ}$, respectively. A vertical arrangement of the zwitterionic CIP adsorbed on the surface of KMS-1 was also confirmed. These results suggested that KMS-1 is an effective adsorbent to remove CIP from water.

Keywords: Chalcogenides; Intercalation; Ciprofloxacin; Cation exchange; Adsorption. 


\section{Introduction}

Ciprofloxacin (CIP) is an important antibiotic widely used as medicine for human and animals [1-3]. For the past decades, excessive drug contamination including CIP has been discharged from hospital and drug manufacturers into the environment. The agricultural soil leaching and incomplete metabolism of CIP in host also contributed to the pollutant source of wastewater. Although wastewater was disposed through sewage treatment plants, CIP might be poorly removed due to the bacteria-inhibiting effect and then accumulated into the surface water gradually [3-5]. Actually, CIP can be detected in wastewater and surface water with concentrations of several hundred ng/L $[6,7]$. The excessive presence of CIP in the environment can develop antibiotic resistance in bacteria as well as lead to deleterious effects on the aquatic organics [8, 9]. Therefore, searching effective methods to remove CIP from waster source has become a vital concern. Various methods have been attempted to remove CIP from water, such as biodegradation [10], oxidation $[11,12]$, photocatalytic degradation [13] and adsorption [3]. Undoubtedly, adsorption is one of the most promising technologies due to its easy operation, economic factor and high efficiency [9, 14-18].

Until now, most of adsorbents used to remove CIP from wastewater are oxide-related materials, such as carbon-based material $[8,19,20]$, natural mineral material [7, 21-25] and synthetic metal oxides [26]. The carbon-based materials, including carbon nanotubes, activated carbon, and carbon xerogel, were usually functionalized with groups containing oxygen atoms for CIP removal. The presence of oxygen atoms on their surface can interact with CIP for higher removal efficiency. It was already shown that the CIP can be removed by typical mineral material such as sodium montmorillonite, rectorite, birnessite, kaolinite and nano-sized magnetite, but the removal mechanisms of these adsorbents may be different [7, 21-25]. The cationic CIP could intercalate into the sodium montmorillonite and make the interlayer spacing changed. While, the zwitterion forms of CIP was removed by surface adsorption of sodium montmorillonite [7]. The uptake of CIP by rectorite and birnessite was resulted from cation exchange between cationic CIP and the exchangeable cation on the surface or between the interlayers [21, 24]. Although the cation exchange was the dominant mechanism of CIP adsorption on kaolinite with desorption of exchangeable cation, there were no intercalation into the kaolinite [23]. The adsorption of CIP at the magnetite surface mediated by carboxylic groups [25]. The results of CIP removal by synthetic metal oxides, such as aluminum hydrous oxides and iron hydrous oxides, showed that only one oxygen atom of the carboxylate group of CIP could bind with the hydrous oxide surface of adsorbents and the other oxygen atom from keto group could further bind with Fe atom of iron hydrous oxides[26]. 


$$
\text { Recently, layered chalcogenides, } \quad \mathrm{K}_{2 \mathrm{x}} \mathrm{Mn}_{\mathrm{x}} \mathrm{Sn}_{3-\mathrm{x}} \mathrm{S}_{6} \quad(\mathrm{x} \quad=\quad 0.5-0.95) \quad(\mathrm{KMS}-1) \quad \text { and }
$$

$\left[\mathrm{CH}_{3} \mathrm{NH}_{3}\right]_{2 \mathrm{x}} \mathrm{Mn}_{\mathrm{x}} \mathrm{Sn}_{3-\mathrm{x}} \mathrm{S}_{6} \cdot 0.5 \mathrm{H}_{2} \mathrm{O}(\mathrm{x}=0.5-1.1)(\mathrm{CMS})$, were shown to effectively and selectively remove heavy metal ions such as $\mathrm{Cd}^{2+}, \mathrm{Pb}^{2+} \mathrm{Hg}^{2+}$ and $\mathrm{Cu}^{2+}$, by ion exchange with a high adsorption capacity over wide $\mathrm{pH}$ range [27-29]. Nowadays, the wastewater is often contaminated by complex pollutants, including heavy metal ions and organic pollutant such as antibiotics. Therefore, it is necessary to develop and evaluate the activities of adsorbents in the presence of complex contaminants. In this context, KMS-1 was applied to remove CIP from aqueous solution in order to evaluate the ability of this important kind of adsorbent for removal of organic pollutant by use of CIP as a pollutant model. To the best of our knowledge, the removal of organic pollutant by layered chalcogenides including KMS-1 from water had never been reported before. The effects of solution $\mathrm{pH}$, contact time, initial concentration and temperature on the removal of CIP were investigated in detail. Furthermore, various kinetics and isotherms of adsorption were also discussed. The adsorption mechanism was proposed through probing the results of X-ray diffraction (XRD), Fourier transformation infrared analyses (FTIR), Field emission scanning electron microscopy (FE-SEM), Transmission electron microscope (TEM), Energy dispersive X -ray (EDX) and zeta potential. Two possible conformations of the exchanged cationic CIP in the interlayer spacing were also proposed. These pioneering results would shed light on the adsorption mechanism of layered chalcogenides for organic pollutant, which might greatly contribute to the application of chalcogenides adsorbents in the treatment of complex wastewater.

\section{Materials and methods}

\subsection{Materials}

$\mathrm{K}_{2} \mathrm{CO}_{3}(\geq 99.0 \%), \mathrm{Sn}(99.99 \%), \mathrm{Mn}(99.99 \%), \mathrm{S}(99.99 \%)$ and ciprofloxacin hydrochloride (CIP. $\mathrm{HCl}$, 98\%) were purchased from Aladdin Company (Shanghai, China), and other reagents were analytical grade and purchased from Sinopharm Chemical Reagent Co., Ltd. (Shanghai, China) without further purification.

Due to the different $\mathrm{pK}_{\mathrm{a}}$ values $\left(\mathrm{pK}_{\mathrm{a} 1}=6.1\right.$ and $\left.\mathrm{pK}_{\mathrm{a} 2}=8.7\right)$, CIP can be cationic, zwitterionic and anionic species in solution with different $\mathrm{pH}$ values [20]. Fig. S1 showed the speciation of CIP at different $\mathrm{pH}$ conditions. CIP exists in a cationic form mainly in an acidic solution with $\mathrm{pH}$ below 6.1 due to the protonation of amine group. CIP exits as an anion group when its $\mathrm{pH}$ is higher than 8.7 due to the loss of a proton from the carboxyl group. When solution $\mathrm{pH}$ was between 6.1 and 8.7 , zwitterionic CIP is the dominant species resulted from the charge balance of the two groups mentioned above.

The preparation of CIP and $\mathrm{Na}^{+} \mathrm{CIP}^{-}$solid: The $\mathrm{pH}$ of about $800 \mathrm{mg} / \mathrm{L}$ of CIP.HCl solution was adjusted 
to 7 or 10 using $\mathrm{NaOH}$ solution by $\mathrm{pH}$ meter (UB-7, Denver, USA). The $\mathrm{pH}$ of the solution was kept for about $6 \mathrm{~h}$. Due to the limited solubility of CIP at different $\mathrm{pH}$, a certain amount of CIP and $\mathrm{Na}^{+} \mathrm{CIP}^{-}$solid will be precipitated. After that, the solid was filtered by filter membrane and dried in vacuum at $60^{\circ} \mathrm{C}$. The CIP and $\mathrm{Na}^{+} \mathrm{CIP}^{-}$solid were finally obtained for $\mathrm{pH}=7$ and $\mathrm{pH}=10$, respectively.

\subsection{Preparation of KMS-1 material}

KMS-1 was prepared according to Manos's methods [28]. In a typical synthesis, $\mathrm{K}_{2} \mathrm{CO}_{3}(5.52 \mathrm{mmol}), \mathrm{Sn}$ (11 mmol), Mn $(5.52 \mathrm{mmol}), \mathrm{S}(33.1 \mathrm{mmol})$ and $\mathrm{H}_{2} \mathrm{O}(7.34 \mathrm{~mL})$ were mixed in a $25 \mathrm{~mL}$ of Teflon-lined autoclave. The autoclave was sealed and placed in furnace at $200{ }^{\circ} \mathrm{C}$ for four days. Then the autoclave was allowed to cool down at room temperature. The product was isolated by filtration and followed by washing with ultrapure water, $\mathrm{CS}_{2}$ and ethanol, respectively. Finally, they were dried in vacuum at $60{ }^{\circ} \mathrm{C}$.

\subsection{Batch adsorption experiment}

All adsorption experiments were carried out in $250 \mathrm{~mL}$ of conical flask by mixing a given dose of KMS-1 with a certain volume of CIP solution (or including competitive ions) in a thermostatic shaker. The initial $\mathrm{pH}$ of CIP solution was adjusted to a certain value using $\mathrm{NaOH}$ and $\mathrm{HCl}$ solution by $\mathrm{pH}$ meter. After adsorption, the mixture was immediately centrifuged, and the supernatant was analyzed for the CIP concentration by a high performance liquid chromatography (HPLC) (1200 infinity, Agilent, USA).

\subsection{Characterization of KMS-1 before and after adsorption}

Powder X-ray diffraction (PXRD) patterns were obtained at room temperature with an X'Pert ProMPD diffractometer (X'Pert Pro, PANalytical B.V., Holand) using $\mathrm{Cu} K_{\alpha}$ radiation $(\lambda=0.15418 \mathrm{~nm})$ beam in the $2 \theta$ range of $5-80^{\circ}$. The elemental composition and content were calculated by Energy dispersive X-ray spectrometer (EDS) (Genesis XM2, EDAX, USA). The particle morphology of KMS-1 before and after adsorption was examined by FE-SEM (S-4800, Hitachi, Japan) and TEM (JEM-2010, JEOL, Japan). The zeta potential of KMS-1 at different pH was measured by Malvern zetameter (Zetasizer, Malvern, UK). The FTIR spectra were acquired by FTIR (Nicolet iS10, Thermo, USA) using the KBr pressing method. The spectra were obtained by accumulating scans at a resolution of $\mathrm{cm}^{-1}$ in the range of $4000-400 \mathrm{~cm}^{-1}$.

\section{Results and discussion}

\subsection{The structure of KMS-1}

The structure of KMS-1 is a layered metal chalcogenide. As shown in the Fig. 1 (inset), each Sn atom were coordinated by six S atoms to form deformed octahedron and the layer was built up by edge-sharing octahedra with $\mathrm{Mn}$ and $\mathrm{Sn}$ atoms occupying the same crystallographic position. $\mathrm{K}^{+}$ions were located 
between the layers and were able to exchange with other cations. The interlayer spacing of KMS-1 was calculated to be $8.51 \AA$ according to Bragg equation. The PXRD of KMS-1 was shown in Fig. 1. The (003) and (006) of Bragg peaks were clearly observed in this study, which were similar to that reported in the reference [30]. It indicated that the layered KMS-1 was successfully prepared. The chemical composite of KMS-1 in this experiment was $\mathrm{K}_{1.88} \mathrm{Mn}_{0.94} \mathrm{Sn}_{2.06} \mathrm{~S}_{6}$ as measured by EDS.

\subsection{Zeta potential}

Zeta potential was used to examine electrical property of the adsorbent surface. As shown in Fig. S2, KMS-1 materials exhibit negative surface in the $\mathrm{pH}$ range of 1-12. Partial KMS-1 would react with $\mathrm{H}^{+}$ under extreme $\mathrm{pH}$ condition (eg. $\mathrm{pH}=1$ ) and some amount of LHMS-1 may be produced according to the reported in the literature [31]. Also slight amount of $\mathrm{H}_{2} \mathrm{~S}$ could be generated due to the decomposition of partial KMS-1, which was verified by the rotten egg smell of the gas in the experiments. These explanations might be account for the comparably lower zeta potential of adsorbent at $\mathrm{pH}$ of 1.0.

\subsection{Effect of contact time}

The contact time is regarded as one of the important factors affecting the adsorption process. Fig. 2 showed the effect of contact time on the adsorption of CIP by KMS-1 at various initial concentrations (10, $50 \mathrm{mg} / \mathrm{L}$ ) with an adsorbent dosage of $133 \mathrm{mg} / \mathrm{L}$ at $\mathrm{pH}$ 4.0. The adsorption capacity increased very quickly with the increase of contact time up to $50 \mathrm{~min}$ at the initial concentration of $10 \mathrm{mg} / \mathrm{L}$. After that, there is no obvious change in CIP adsorption. When the initial concentration was $50 \mathrm{mg} / \mathrm{L}$, the adsorption capacity increased greatly at first hour and then increased slowly until $420 \mathrm{~min}$ to reach the adsorption equilibrium. It can be explained by that $\mathrm{K}^{+}$available for ion exchange decreased with the reaction continuing. The adsorption capacity increased with the increase of initial CIP concentration, which indicates that adsorption capacity is dependent on the initial CIP concentrations.

\subsection{Effect of initial concentration and temperature}

The effect of the initial CIP concentration varied in the range of $10-212 \mathrm{mg} / \mathrm{L}(\mathrm{pH}=4$, adsorbent dosage $=133 \mathrm{mg} / \mathrm{L}$ ) on the adsorption capacity was investigated at temperature of 10,25 and $40{ }^{\circ} \mathrm{C}$, respectively. As shown in Fig. 3, the adsorption capacity of cationic CIP was strongly dependent on the initial concentration and it increased very quickly with the increase of initial concentration below $50 \mathrm{mg} / \mathrm{L}$. This attributed to the increase in the driving force that enhanced the effective collision probability between CIP and the available ion exchangeable $\mathrm{K}^{+}$. As a fact, due to the limited interspacing and larger size of the CIP molecules, not all of the $\mathrm{K}^{+}$can be exchanged with CIP. Therefore, even if the available $\mathrm{K}^{+}$still exists 
in the KMS-1, the adsorption capacity gradually reached equilibrium and the maximum adsorption capacity was acquired. It was also shown that the adsorption capacity increased with increase of the reaction temperature.

\subsection{Effect of heavy metal ions}

The KMS-1 allows rapid ion exchange kinetics of the intercalated $\mathrm{K}^{+}$ions with heavy metal ions such as $\mathrm{Pb}^{2+}$, and $\mathrm{Cd}^{2+}, \mathrm{Ni}^{2+}$ with good adsorption capacity $[28,32]$. In order to examine the selectively of KMS-1 for CIP and other heavy metal ions, the $\mathrm{Pb}^{2+}, \mathrm{Cd}^{2+}, \mathrm{Ni}^{2+}$ or $\mathrm{Zn}^{2+}$ was added into the CIP solution, respectively, and the molar concentration of each heavy metal ions was same as that of CIP. Fig. S3 showed that the adsorption capacity of CIP declined in the presence of each kind of heavy metal ion. The results may be explained that the heavy metal ions competed with the CIP during the process of ion exchanged with $\mathrm{K}^{+}$. The effects of competition by various heavy metal ions were different. The degree of inhibition on adsorption by the heavy metal ions followed the sequence: $\mathrm{Pb}^{2+}>\mathrm{Zn}^{2+}>\mathrm{Cd}^{2+}>\mathrm{Ni}^{2+}$. According to the hard soft acid base (HSAB) theory, $\mathrm{Cd}^{2+}$ is soft acid while $\mathrm{Pb}^{2+}, \mathrm{Zn}^{2+}$ and $\mathrm{Ni}^{2+}$ are border acid. Compared with other heavy metal ions, the sulfide is prone to bind with $\mathrm{Cd}^{2+}$. Actually, the $\mathrm{Cd}^{2+}$ not only replaced the $\mathrm{K}^{+}$ions but also the $\mathrm{Mn}^{2+}$ ions of the layers, which indicated that more adsorption site can be obtained during the process of $\mathrm{Cd}^{2+}$ adsorption [28]. Therefore, the inhibited effect of $\mathrm{Cd}^{2+}$ on the removal of CIP was not the most serious. The attraction between nucleus and outer electron would decrease with the increase of atomic radius and the larger atom is much easier to bind with sulfur atom. The radius of the competitive heavy metal ions follows the sequence: $\mathrm{Pb}^{2+}>\mathrm{Zn}^{2+}>\mathrm{Ni}^{2+}$. As a result, the degree of inhibition on adsorption by the heavy metal ions followed the sequence: $\mathrm{Pb}^{2+}>\mathrm{Zn}^{2+}>\mathrm{Ni}^{2+}$.

The co-sorption of CIP and heavy metal ions $\left(\mathrm{Pb}^{2+}, \mathrm{Cd}^{2+}, \mathrm{Ni}^{2+}\right.$ or $\left.\mathrm{Zn}^{2+}\right)$ by adsorbents was seldom reported in the literature. The only available example was that the CIP and $\mathrm{Ni}^{2+}$ were adsorbed together by activated carbon [3]. It was found that the existence of $\mathrm{Ni}^{2+}$ enhanced the adsorption of CIP on activated carbon in the $\mathrm{pH}$ range of 3.4 - 6.5. The reason was that part of $\mathrm{Ni}^{2+}$ ions interacted with CIP to form complexes with positive surface charge, which were more easily to be adsorbed on the surface of activated carbon than zwitterionic and anionic CIP. While the CIP competed with $\mathrm{Ni}^{2+}$ during the process of ion exchanged with $\mathrm{K}^{+}$at $\mathrm{pH} 4$ in this study. The different adsorption mechanisms can attribute to the different performance of adsorption behavior.

\subsection{Adsorption kinetics}

In order to further study the adsorption process of CIP onto KMS-1, kinetic investigation was conducted at the concentration of $10 \mathrm{mg} / \mathrm{L}$ and $50 \mathrm{mg} / \mathrm{L}$. The adsorption kinetics was analyzed by using pseudo-first-order and pseudo-second-order models. The integrations of the pseudo-first-order kinetic 
equation and pseudo-second-order kinetic equation can be represented as follows:

$$
\begin{aligned}
& \log \left(q_{e}-q_{t}\right)=\log q_{e}-\frac{k_{1} t}{2.303} \\
& \frac{t}{q_{t}}=\frac{1}{k_{2} q_{e}^{2}}+\frac{t}{q_{e}}
\end{aligned}
$$

Where $k_{1}$ is the rate constant of pseudo-first-order adsorption $\left(\mathrm{min}^{-1}\right), k_{2}$ is the equilibrium rate constant of pseudo-second-order adsorption $(\mathrm{g} /(\mathrm{mg} \cdot \mathrm{min})), q_{\mathrm{e}}$ and $q_{\mathrm{t}}$ are the amounts of metal ions adsorbed $(\mathrm{mg} / \mathrm{g})$ at equilibrium and at any instant of time, respectively, and $t$ is the contact time (min).

The calculated kinetic parameters for pseudo-first-order and pseudo-second-order models were listed in Table S1. The correlative coefficient $\left(R^{2}\right)$ of the pseudo-second-order model was obviously better than that of the pseudo-first-order model at different concentrations. The theoretical $q_{\text {ecal }}$ value calculated from the pseudo-second-order model was also very close to the experimental value. These results indicated that the entire kinetic data fitted well with pseudo-second-order models. The adsorption rate constant decreased with the increase of initial concentration. The pseudo-second-order model is based on the assumption that the rate limiting step might be a chemical adsorption in the adsorption process. It also further indicated that CIP can be chemical binding with the negatively surface of KMS- 1 after ion exchanging with $\mathrm{K}^{+}$.

In the equation, the $k_{2} q_{\mathrm{e}}{ }^{2}$ is the initial rate $(\mathrm{mg} /(\mathrm{g} \cdot \mathrm{min}))$ [23]. The initial rates for initial concentration of 10 and $50 \mathrm{ppm}$ were $9.532 \mathrm{mg} /(\mathrm{g} \cdot \mathrm{min}$ ) (or $1726 \mathrm{mmol} /(\mathrm{kg} \cdot \mathrm{h})$ ) and $31.456 \mathrm{mg} /(\mathrm{g} \cdot \mathrm{min}$ ) (or 5696 $\mathrm{mmol} /(\mathrm{kg} \cdot \mathrm{h}))$, respectively. The initial rate increased with increase in initial concentration. These initial rates of KMS-1 were obviously higher than $1667 \mathrm{mmol} /(\mathrm{kg} \cdot \mathrm{h})$ for CIP adsortion on kaolinite [23], 5.3 $\mathrm{mmol} /(\mathrm{kg} \cdot \mathrm{h})$ for CIP adsorption on activated carbon [3] and $751 \mathrm{mmol} /(\mathrm{kg} \cdot \mathrm{h})$ for CIP adsorption on modified coal fly ash [2], respectively.

\subsection{Rate controlling step analysis}

The rate controlling step is a significant factor in the adsorption process. In order to realize the exact diffusion mechanism, the adsorption kinetic data were further analyzed by the intraparticle diffusion model, which is expressed as:

$q_{t}=k_{i} t^{1 / 2}+C_{i}$

where $k_{\mathrm{i}}$ is the intraparticle diffusion rate constant $\left(\mathrm{mg} /\left(\mathrm{g} \cdot \mathrm{min}^{0.5}\right)\right)$ and $C_{\mathrm{i}}$ is a constant that provides an idea about the thickness of the boundary layer. In this model, the overall rate of adsorption involves four steps: bulk diffusion, film diffusion, interparticle diffusion and adsorption at the active site. The first step (bulk diffusion) can be neglected if the solution was stirred sufficiently during the process of adsorption. The 
fourth step (adsorption at the active site) is very rapid and therefore it cannot be regard as rate controlling steps $[33,34]$.

According to this model, if the adsorption process is only controlled by intraparticle diffusion, then the plot of $q_{\mathrm{t}}$ versus $t^{1 / 2}$ will be a straight line. If the date has multi-linear plots, then two steps control the process. In the present research, as shown in Fig. S4, the plots presented three linear portions on the basis of intraparticle diffusion model at different initial concentration. The first portion of curves at different initial concentration indicated that the film diffusion of CIP through boundary layer onto the external surface of KMS-1 with high uptake rate. The second linear portion belongs to intraparticle diffusion. The third section represented final equilibrium stage where intraparticle diffusion begins to slow down. Furthermore, the plot did not pass through the origin. This indicated that the rate controlling steps were both external film diffusion and intraparticle diffusion during the adsorption process.

The intraparticle diffusion rate constant $k_{\mathrm{i}}$ and $C_{\mathrm{i}}$ were calculated from the slop of the section linear section, which were shown in Table $\mathrm{S} 2$. The larger value of $C_{\mathrm{i}}$ revealed that film diffusion had a larger role as the rate-limiting step. The value of $C_{\mathrm{i}}$ increased with the increasing of initial concentration. This suggested that the film diffusion became more important at high initial concentration.

\subsection{Adsorption isotherms and thermodynamic parameters}

Adsorption isotherms models can be used to describe the adsorption process and investigate the adsorption mechanism. In this study, Langmuir and Freundlich isothermal equations were employed to analysis the experimental data, which can be expressed, respectively, as

Langmuir equation: $\frac{C_{e}}{q_{e}}=\frac{C_{e}}{q_{m}}+\frac{1}{q_{m} K_{\mathrm{L}}}$

Freundlich equation: $\log q_{e}=\log K_{f}+\frac{1}{n} \log \mathrm{C}_{e}$

Where $C_{\mathrm{e}}$ is the equilibrium concentration of metal ion in the solution $(\mathrm{mg} / \mathrm{L}), q_{\mathrm{e}}$ and $q_{\mathrm{m}}$ are the equilibrium adsorption capacity and the maximum adsorption of adsorbent $(\mathrm{mg} / \mathrm{g})$, respectively, $K_{\mathrm{L}}$ is the Langmuir adsorption equilibrium constant $(\mathrm{L} / \mathrm{mg})$ related to the free energy and affinity of adsorption, $K_{\mathrm{f}}$ is the constant indicative of the relative capacity of the adsorbent, and $1 / \mathrm{n}$ is an empirical parameter related to the adsorption intensity. The essential characteristic of the Langmuir isotherm dimensionless separation factor $\left(R_{L}\right)$

$$
R_{L}=\frac{1}{1+K_{L} C_{0}}
$$


The value of separation factor $R_{L}$ indicates either the adsorption isotherm to be unfavorable $\left(R_{\mathrm{L}}>1\right)$, favorable $\left(0<R_{\mathrm{L}}<1\right)$, linear $\left(R_{\mathrm{L}}=1\right)$ or irreversible $\left(R_{L}=0\right)$.

The Langmuir and Freundlich models fitting results were summarized in Table S3. From the comparison of correlation coefficients $\left(R^{2}\right)$, the data were fit better by Langmuir model than by Freundlich model for CIP adsorption at different temperatures. According to Langmuir model, the maximum adsorption capacities of CIP by KMS-1 were $199.6,230.9$ and $269.5 \mathrm{mg} / \mathrm{g}$ at temperature of 10,25 and $40{ }^{\circ} \mathrm{C}$, respectively. The $R_{\mathrm{L}}$ value in this study ranged from 0.05 to 0.65 at different temperatures, suggesting a favorable adsorption of CIP onto KMS-1. In addition, the $R_{\mathrm{L}}$ value decreased with increase of the initial CIP concentration, indicating that the adsorption process was more favorable at higher concentration [35]. The Langmuir isotherm is an empirical model that is based on monolayer coverage of the adsorbate onto the active sites of the adsorbent. The cationic CIP interacted with the negative surface of KMS-1 after ion exchange with $\mathrm{K}^{+}$. The contribution from the adsorption of zwitterionic CIP on the surface of KMS-1 can be ignored. Therefore, adsorption isotherm of CIP onto KMS-1 can be well described by Langmuir model.

In order to evaluate the performance of KMS-1 for CIP removal from aqueous solution, as shown in Table 1, the maximum adsorption capacities of CIP from present study were compared with that of other adsorbents in previous study. The adsorption capacities of CIP by KMS-1 are 199.6, 230.9 and 269.5 mg/g at temperature of 10,25 and $40{ }^{\circ} \mathrm{C}$, respectively. Comparably, the adsorption capacities of CIP were below $200 \mathrm{mg} / \mathrm{g}$ for most of adsorbents though they were more than $200 \mathrm{mg} / \mathrm{g}$ for the montmorillonite and activated carbon. It is clear that KMS-1 shows higher adsorption capacities than most of the adsorbents.

The adsorption capacity increased with increase in temperature, indicating that the adsorption is endothermic, which was further explained by evaluation of thermodynamic parameter. The thermodynamic parameters of the adsorption process including Gibbs free energy $(\Delta G)$, enthalpy $(\Delta H)$, and entropy $(\Delta S)$ are commonly used to describe the spontaneity and heat of system, which were determined by using the following equations [36].

$\Delta G=-R T \ln K_{L}$

$\ln K_{L}=-\frac{\Delta H}{R T}+\frac{\Delta S}{R}$

Where $K_{\mathrm{L}}(\mathrm{L} / \mathrm{mol})$ is the Langmuir constant, $R(\mathrm{~kJ} / \mathrm{mol} / \mathrm{K})$ is the gas constant; $T(\mathrm{~K})$ is the reaction temperature. By plotting a graph of $\ln K_{\mathrm{L}}$ versus $T^{1}$, the value $\Delta H$ and $\Delta S$ can be calculated from the slopes and intercepts. The negative $\Delta G$ values $(-26.9,-28.7,-31.1) \mathrm{kJ} / \mathrm{mol}$ at 10,25 and $40{ }^{\circ} \mathrm{C}$ reveals the 
spontaneous adsorption of CIP on KMS-1 and also the feasibility of the adsorbent. The positive $\Delta H$ value $(11.8 \mathrm{~kJ} / \mathrm{mol})$ indicates that the adsorption of CIP by KMS-1 is endothermic. The positive value of $\Delta S$ $(136.5 \mathrm{~J} / \mathrm{mol} \mathrm{K})$ indicates that the randomness increases at the solid/solution surface during the adsorption.

\subsection{The effect of $\mathrm{pH}$}

The solubility of CIP was low at $\mathrm{pH}$ of 5-10 and the lowest solubility of $0.2 \mathrm{mmol} / \mathrm{L}$ (about $66.3 \mathrm{mg} / \mathrm{L}$ ) was found at $\mathrm{pH}$ of 7 [23]. In this study, the initial concentration of CIP was $50 \mathrm{mg} / \mathrm{L}$ with an adsorbent dosage of $133 \mathrm{mg} / \mathrm{L}$ at $\mathrm{pH} 1-12$. As shown in Fig. 4, the adsorption of CIP by KMS-1 was highly $\mathrm{pH}$-depended. The adsorption capacity increased with an increase of $\mathrm{pH}$ from 1 to 4 and decreased greatly with a $\mathrm{pH}$ rise from 5 to 12 . The maximum adsorption capacity was observed at $\mathrm{pH} 4$.

A slight amount of hydrogen sulfide can be produced by the reaction between the $\mathrm{H}^{+}$and sulfur atoms of KMS-1 at $\mathrm{pH} 1$, which was the cause of the low adsorption capacity. Due to more available $\mathrm{H}^{+}$ions at low $\mathrm{pH}$ value of 1 - 3 in the solution, $\mathrm{H}^{+}$would compete with cationic CIP strongly to exchange with $\mathrm{K}^{+}$during ion exchange process. The $\mathrm{pH}$ effect on the adsorption is also resulted from the presence of various CIP species at different $\mathrm{pH}$ values. The high adsorption capacity was observed in the $\mathrm{pH}$ range of $4-5$ because of the presence of high percentage of cationic CIP. The adsorption capacity decreased with decrease of the percentage of cationic CIP in the $\mathrm{pH}$ range of 5 - 8. The main species of CIP were zwitterionic and anionic forms at $\mathrm{pH} 9-10$, and CIP was only removed by KMS-1 with low adsorption capacity. The adsorption capacity of KMS-1 for CIP removal was almost zero at $\mathrm{pH} 11-12$. These results indicated that the anionic CIP cannot be removed but the zwitterionic CIP can also be removed by KMS-1. Furthermore, cation exchange played an important role in the removal of CIP.

Other adsorbents displayed a different performance for CIP removal at $\mathrm{pH} 3$ - 11. For montmorillonite, the effect of $\mathrm{pH}$ on the CIP removal was slight when the $\mathrm{pH}$ of solution was in the range of 3 - 9 [7]. The similar phenomenon was also found for the adsorption of CIP by birnessite, $6 \%$ grapheme oxide/calcium alginate and kaolinite, respectively [9, 23, 24]. For montmorillonite, the cationic form of CIP was removed by ions exchange, and the zwitterionic form of CIP was removed by adsorption. It suggested that the positively charged amine group played an important role in CIP removal by montmorillonite via cation exchange with the cationic form of CIP. However, the cationic and zwitterionic form of CIP can be adsorbed by birnessite via cation exchange. And a higher amount of CIP adsorption on kaolinite in both cationic and zwitterionic forms was also observed. Therefore, the adsorption capacity of these adsorbents was almost same at $\mathrm{pH} 3-11$. The adsorption of CIP by nano- $-\mathrm{Fe}_{3} \mathrm{O}_{4}$ and wet (or dry) carbons increased 
with the increase of initial $\mathrm{pH}$ and reached a maximum value at $\mathrm{pH} 6$, then decreased a lot. The reason was that the zwitterionic CIP was main species, which can be adsorbed by these adsorbents [5, 25]. From these results, it can be concluded that the adsorption of CIP by adsorbents was related to the nature of the adsorbents and the existence of $\mathrm{pH}$-dependent species of CIP. The cation exchange was the dominant route of CIP removal by KMS-1, which is different with those of other adsorbents. Due to the great decrease of adsorption capacity in the $\mathrm{pH}$ rang of 5 - 12, the adsorption of zwitterionic CIP by KMS-1 played a minor part in the adsorption process. Notably the CIP can be removed by KMS-1 at very low pH while performance of these oxides for removal of CIP was limited due to the instability of these oxides at the lower $\mathrm{pH}$ value.

Figure S5 shows the concentration of desorption of exchangeable $\mathrm{K}^{+}$in the solution at different $\mathrm{pH}$. The variation tendency of concentration of $\mathrm{K}^{+}$was similar with removal quantity of CIP, and the amount of $\mathrm{K}^{+}$ in solution was related to that of absorbed CIP at $\mathrm{pH} 1-5$, confirming experimentally that cation exchange was responsible for CIP adsorption as previously proposed. The concentration of $\mathrm{K}^{+}$was zero in the $\mathrm{pH}$ range of 9 - 12, which was agreement with the unchanged XRD pattern after adsorption.

\subsection{Characterization of KMS-1 before and after adsorption}

\subsubsection{XRD analyses}

Fig. 5 shows the XRD patterns of KMS-1 before and after adsorption of CIP at different pH solutions. The XRD pattern of KMS-1 has two characteristic peaks named $\mathrm{P}_{0}$ (corresponding diffraction angle $2 \theta_{0}$ ) and $\mathrm{P}_{1}\left(2 \theta_{1}\right)$, respectively. According to the $2 \theta_{0}$ values, the interlayer spacing can be calculated by Bragg equation to be $8.51 \AA\left(\mathrm{d}_{0}\right)$. Although some amount of the CIP can be removed by KMS-1 at pH $9-10$, the XRD patterns did not changed, which suggested that the zwitterionic CIP and anionic CIP could not be exchanged with $\mathrm{K}^{+}$and the zwitterionic CIP can only be adsorbed on the surface of KMS-1 according to the section 3.9. Two very slight peaks named $\mathrm{P}_{2}$ and $\mathrm{P}_{4}$ can be observed at $\mathrm{pH} 8$, indicating that the cationic CIP had been intercalated into the layer due to only a little amount of cationic CIP available at this $\mathrm{pH}$ value. In addition, the two characteristic peaks $\left(\mathrm{P}_{0}\right.$ and $\left.\mathrm{P}_{1}\right)$ of KMS-1 were nearly not changed, which indicated that only one type of intercalation newly formed at $\mathrm{pH} 8$.

After adsorption there were four new Bragg peaks named $P_{2}$ (corresponding diffraction angle $2 \theta_{2}$ ), $P_{3}$ $\left(2 \theta_{3}\right), \mathrm{P}_{4}\left(2 \theta_{4}\right)$ and $\mathrm{P}_{5}\left(2 \theta_{5}\right)$ appeared in the $\mathrm{pH}$ rang of $4-7$, respectively, and the $\mathrm{P}_{0}$ and $\mathrm{P}_{1}$ peaks disappeared. The $\mathrm{P}_{0}$ and $\mathrm{P}_{1}$ peaks partly shifted to $\mathrm{P}_{2}$ and $\mathrm{P}_{4}$, respectively. Another change was that the $\mathrm{P}_{0}$ and $\mathrm{P}_{1}$ peaks partly shifted to $\mathrm{P}_{3}$ and $\mathrm{P}_{5}$, respectively. It indicated that there are two intercalations formed 
during the adsorption of cationic CIP in the $\mathrm{pH}$ rang of $4-7$. The $\mathrm{P}_{2}$ and $\mathrm{P}_{4}$ peaks were two characteristic peaks of intercalation with interlayer spacing $d_{1}$ (type A), which can be calculated by Bragg equation from $2 \theta_{2}$ values, while, $\mathrm{P}_{3}$ and $\mathrm{P}_{5}$ peaks were belong to another type of new intercalation with interlayer spacing $d_{2}$ (type B), which can be calculated by Bragg equation from $2 \theta_{3}$ values. The two types of new intercalation were formed after adsorption of KMS-1 in the $\mathrm{pH}$ range of $4-7$, which might be due to two conformation of the CIP in the adsorbent. Usually, this pheromone was not observed in layered oxides for CIP intercalation such as montmorillonite, rectorite and birnessite [6, 22, 24]. For these layered oxides, the interlayer spacing increased with the increase in adsorption capacity and only one type of intercalations newly formed after the adsorption of CIP at acid solution. Another report that the intercalation of tetracycline with two conformations into the layer of smectite was verified [37], which was similar to our results.

After adsorption, the $\mathrm{P}_{0}$ and $\mathrm{P}_{1}$ peaks shifted to $\mathrm{P}_{3}$ and $\mathrm{P}_{5}$ at $\mathrm{pH} 1-3$, respectively, which indicated the only existence of one type of cationic CIP intercalation (type B). The $\mathrm{H}^{+}$may have influenced on the production of cationic CIP intercalation during the process of adsorption. With the competition of more amount of $\mathrm{H}^{+}$, the layered structure might be more stable when the interlayer spacing was smaller. It was interesting that there were two new types of intercalation at $\mathrm{pH} 4-7$ and one new type of intercalation at pH 1 - 3. This result was also different from the intercalation of CIP by montmorillonite [7] and rectorite at acid solution [21]. For these layered oxides, only one type of intercalations was newly formed after the adsorption of CIP at different $\mathrm{pH}$ solutions.

In order to investigate the structures of intercalation of cationic CIP by KMS-1 in detail, the XRD patterns of KMS-1 with various adsorption capacity of CIP at $\mathrm{pH}$ of 4 were shown in the Fig. 6 . When the maximum adsorption capacity was achieved $(230 \mathrm{mg} / \mathrm{g})$, after exchange, the interlayer spacing of newly formed intercalations were $13.4 \AA$ and $9.7 \AA$, corresponding to the $\mathrm{P}_{2}$ peak $\left(2 \theta_{2}=6.6^{\circ}\right)$ and $\mathrm{P}_{3}$ peak $\left(2 \theta_{3}=\right.$ $\left.9.1^{\circ}\right)$, respectively. The results indicated that in all conditions two types of new intercalation were formed after adsorption of KMS-1 at pH of 4 . In contrast to that of $\mathrm{P}_{3}$ peak, the intensity of $\mathrm{P}_{2}$ peak increased with increase of the adsorption capacity from 75 to $230 \mathrm{mg} / \mathrm{g}$. While, the intensity of $\mathrm{P}_{3}$ peak decreased with increase of the adsorption capacity from 75 to $230 \mathrm{mg} / \mathrm{g}$. These results indicated that the percentage of new intercalation with larger interlayer spacing $13.4 \AA$ increased with the increase of adsorption capacity of CIP. While, the percentage of new intercalation with smaller interlayer spacing $9.7 \AA$ decreased with the adsorption capacity of CIP. This can be easily understood that the new intercalation with larger interlayer 
spacing is required for more valid void for loading more capacity of exchanged CIP. It is interesting that for the oxides adsorbents, the interlayer spacing of montmorillonite and birnessite also increased with the increase of the adsorption capacity of CIP at acid solution [7, 24].

Compared to the XRD pattern of raw KMS-1, it showed the adsorbed KMS-1 had weak intensity of the peaks and poor crystallinity. This phenomenon was also observed for the montmorillonite intercalated with CIP and other types of organic substances $[6,37]$. It was attributed to the heterogeneous intercalation and delamination of the layers.

\subsubsection{SEM analyses}

Fig. 7 shows the SEM images of KMS-1 before and after adsorption of CIP at different pH solutions. The surfaces of KMS-1 before and after adsorption in the $\mathrm{pH}$ range of 1 - 3 were all smoothly, which indicated that there was no CIP adsorbed on the surface of KMS-1. Few of small particles were observed on the surface of KMS-1 after adsorption of CIP at $\mathrm{pH} 4$. More of small particles were indicated on the surface of KMS-1 after adsorption of CIP at pH 5 - 10. While the surface of KMS-1 after adsorption at $\mathrm{pH}$ 11 was smooth without small particles. The adsorption capacity of KMS-1 was almost zero at $\mathrm{pH}$ of 11 , which indicated that the anionic CIP cannot be adsorbed by KMS-1. Therefore, it can be concluded that the small particles were originated from the adsorption of zwitterionic CIP on the surface of KMS-1.

\subsubsection{TEM and EDX analyses}

In order to identify the particles on the surface of KMS-1 after adsorption in details, the KMS-1 sample after adsorption at pH 10 was examined by TEM and EDX. As shown in Fig. 8, the particles were clearly absorbed on the surface of KMS-1 with different sizes. The curve (a) of the EDX spectra in the Fig. 9 showed that the elements of KMS-1 are composed of K, Mn, Sn and S elements. As the samples were on the copper grid with carbon film, the samples can also be detected with $\mathrm{Cu}$ and $\mathrm{C}$ elements. Comparably, from curve (b) of the EDX spectra, the presence of $\mathrm{N}$ and $\mathrm{F}$ elements can be identified as the presence of CIP from the EDX of the particles on the surfaces of the KMS-1 after adsorption. At the pH of 10 , the CIP was existed as zwitterionic CIP and anionic CIP. As the adsorption of anionic CIP by KMS-1 was not occurred (see explained above), the small particles in the surface of can be attributed to the adsorption of zwitterionic CIP on the surface of KMS-1.

\subsubsection{FTIR analyses}

Fig. 10 showed the FTIR spectra of CIP. $\mathrm{HCl}$ and solids precipitated at $\mathrm{pH}$ of 7 or 10 at the finger print region of $1200-1800 \mathrm{~cm}^{-1}$, in which the adsorption spectra were mainly influenced by the vibration bands. 
The CIP.HCl molecule has carboxylic group and the protonation of amine group that can be equal to the cationic CIP in the solution at $\mathrm{pH} \leq 4$. For the CIP. $\mathrm{HCl}$ molecule, the peaks at $1708 \mathrm{~cm}^{-1}$ can be assigned to the $\mathrm{C}=\mathrm{O}$ stretching of carboxylic group. The $\mathrm{C}=\mathrm{O}$ stretching band shifted to $1726 \mathrm{~cm}^{-1}$ with slight peak for solid precipitated at $\mathrm{pH}$ of 7 but absent for solid precipitated at $\mathrm{pH}$ of $10[7,26,38,39]$. In other study, when the $\mathrm{pH}$ of solution increased from 2 to 9 , the $\mathrm{C}=\mathrm{O}$ stretching band also became weaker and it disappeared at $\mathrm{pH}$ of 9 , which was similar with our results [26]. The reason can be that with increasing $\mathrm{pH}$, the cationic CIP decreased and the deprotonation of the carboxylic group results in the $\mathrm{C}=\mathrm{O}$ bond becoming two more or less equivalent $\mathrm{C}-\mathrm{O}$ bonds. Therefore, the absorbance in the $\mathrm{C}=\mathrm{O}$ stretching region becomes weaker until disappearance. The peaks at $1589 \mathrm{~cm}^{-1}$ and $1384 \mathrm{~cm}^{-1}$ (or $1383 \mathrm{~cm}^{-1}$ ) can be assigned to asymmetric $\left(V_{a s} \mathrm{COO}^{-}\right)$and symmetric $\left(V_{s} \mathrm{COO}^{-}\right)$stretching vibrations of the $-\mathrm{COO}^{-}$group, respectively [26, 40]. The vibration peaks at 1398 and $1394 \mathrm{~cm}^{-1}$ were due to the protonation of the amine group of the piperazine moiety.

Fig. 11 shows the FTIR spectra of KMS-1 after adsorption of CIP at different $\mathrm{pH}$ values. As can be seen, the $\mathrm{C}=\mathrm{O}$ stretching vibration band of carboxylic group disappeared at various $\mathrm{pH}$ value. This phenomenon can also been shown in other studies [24, 26]. For the adsorbent of aluminum and iron hydrous oxides, due to the binding between the $\mathrm{O}$ of the carboxylate group and hydrous oxide surface, the $\mathrm{C}=\mathrm{O}$ stretching vibration band of carboxylic acid at $1708 \mathrm{~cm}^{-1}$ disappeared after adsorption of CIP [26]. The disappearance of $\mathrm{C}=\mathrm{O}$ stretching vibration band was also observed when the CIP adsorbed by birnessite because of the interaction between carboxylic acid and the $\mathrm{O}$ of birnessite surface [7]. Referred to the adsorption of CIP onto hydrous oxide surface and birnessite, the absence of $\mathrm{C}=\mathrm{O}$ stretching vibration band of carboxylic group could be interpreted by that the strong interaction between the carboxylic group and KMS-1 surface, which restricted the $\mathrm{C}=\mathrm{O}$ stretching vibration and the deprotonation of carboxyl group at the $\mathrm{pH}<\mathrm{pK}_{\mathrm{a} 1}$ [23].

The band at $1398 \mathrm{~cm}^{-1}$ and $1394 \mathrm{~cm}^{-1}$, corresponding to the protonation of amine group in the piperazine moiety, shifted to $1400 \mathrm{~cm}^{-1}$ and $1408 \mathrm{~cm}^{-1}$ respectively, indicating that the electronic attraction between the protonated amine group and the negative surface charges of KMS-1. This phenomenon was also observed when the CIP was intercalated with montomorillonite and rectorite by ion exchange [6, 22]. In addition, the zwitterionic CIP can be adsorbed on the surface of KMS-1 through the electronic attraction between the protonated amine group and the negative surface charges of KMS-1.

The band at $1589 \mathrm{~cm}^{-1}$ and $1384 \mathrm{~cm}^{-1}$ (or $1383 \mathrm{~cm}^{-1}$ ), corresponding to the $V_{a s} \mathrm{COO}^{-}$and $V_{s} \mathrm{COO}^{-}$ 
stretching vibrations, shifted to $1561 \mathrm{~cm}^{-1}$ and $1382 \mathrm{~cm}^{-1}$, respectively [26]. Although the $V_{a s} \mathrm{COO}^{-}$ stretching vibrations was absent for the $\mathrm{CIP} \cdot \mathrm{HCl}$, its band was observed at $1561 \mathrm{~cm}^{-1}$ after adsorption of $\mathrm{CIP}$ at $\mathrm{pH} 2$ and 4. It can be concluded that these changes was originated from the electronic attraction between the carboxylic group and the negative surface charges of KMS-1 after the process of intercalation. The $V_{a s} \mathrm{COO}^{-}$band was absent after adsorption of $\mathrm{CIP}$ at $\mathrm{pH} 10$.

\subsection{The mechanism of adsorption of CIP}

The conformation of CIP in the interlayer spacing of KMS-1 could be deduced from the results of XRD, FTIR, SEM and TEM analyses. The interlayer spacing of KMS-1 expanded to $13.4 \AA$ and $9.7 \AA$ when the maximum adsorption capacity was $230 \mathrm{mg} / \mathrm{g}$. The total molecule length of CIP was $12.2 \AA$, which is shorter than the interlayer spacing of $13.4 \AA$. Therefore, even if the intercalated CIP presented a vertical orientation, the length of CIP molecule is not enough to fill the interlayer spacing of KMS-1. In the literature, the interlayer spacing of montmorillonite and rectorite after CIP intercalation was $7.23 \AA$ and $5.90 \AA$, respectively, and the exchanged CIP exhibited a titled orientation with an angle of about $35^{\circ}$ and $29^{\circ}$, respectively $[21,22]$. While, other reports showed that the interlayer spacing of montmorillonite was $11.2 \AA$ and $13.8 \AA$ with the CIP intercalation at pH 3.0 and 11.0, respectively [7]. The more large of interlayer spacing after exchanged suggested that the intercalation CIP adopted a titled orientation of the di-molecular with the tilted angle of $51^{\circ}$ and $73^{\circ}$, respectively [7]. The $\pi-\pi$ stacking of two CIP molecules presented partial overlapping of the interplanar structure and opposite directions of piperazine groups. The molecular length of this dimer was $14.4 \AA$ with a separation distance of $3.5-3.9 \AA$ between the two molecules [7]. It can be concluded that the intercalation of CIP also exhibited a titled orientation of the di-molecular in this study. As shown in Fig. 12, the titling angles of the chain were calculated to be $68^{\circ}$ and $42^{\circ}$, respectively. The two end of the dimer would adopt electrostatic attraction with KMS- 1 surface through its protonated amine groups. According to the FTIR analyses, the affinity adsorption between the carboxylic acid and the KMS-1 surface also existed.

It was reported that a vertical arrangement of zwitterionic CIP was adsorbed on the montmorillonite [7] and soils and soil mineral [41]. Based on this arrangement, it maximized the attraction between the ammonium groups and the negatively charged surface and also minimized the repulsion between the anionic moiety and the surface due to the greater distance [41]. The KMS-1 has negative surface in the $\mathrm{pH}$ range of 1 - 11. It also can be concluded that the positioning and orientation of zwitterionic CIP was hypothesized by a vertical arrangement on the interlayer spacing of KMS-1 with the attraction between the 
ammonium groups and the negatively charged surface. The adsorption capacity of KMS-1 for CIP was almost zero at $\mathrm{pH}$ 11, which indicated that the anionic CIP cannot be adsorbed by KMS-1 due to the negatively charged surface.

\section{Conclusion}

KMS-1 is an excellent adsorbent for the removal of CIP from water. The adsorption process was described well by the pseudo-second-order kinetic model and the rate controlling steps were both external film diffusion and intraparticle diffusion. The equilibrium adsorption date was fitted by Langmuir model. The adsorption of CIP by KMS-1 is endothermic. The maximum adsorption capacities of KMS-1 were 199.6, 230.9 and $269.5 \mathrm{mg} / \mathrm{g}$ at temperature of 10,25 and $40{ }^{\circ} \mathrm{C}$, respectively. The heavy metal ions had great effect on the removal efficiency of CIP. The solution $\mathrm{pH}$ had strong effects on the adsorption capacity and species of CIP adsorbed. The cationic CIP was intercalated in the KMS-1 with titled orientation of di-molecules CIP. A vertical arrangement of the zwitterionic CIP adsorbed on the KMS-1 surface was hypothesized.

\section{Acknowledgments}

This work was financially supported by National Natural Science Foundation of China (No 51278481), International Science \& Technology Cooperation Program of China (2011DFB91710), Xiamen Science \& Technology Major Program (No. 3502Z20131018) and the Foundation of State Key Laboratory of Structural Chemistry. We also thank Prof. Dr. Daniel Giammar in the Department of Energy, Environmental \& Chemical Engineering, Washington University in St. Louis for constructive and helpful suggestions.

\section{References:}

[1] M. Graouer-Bacart, S. Sayen, E. Guillon, J. Colloid Interface Sci. 408 (2013) 191-199.

[2] C.L. Zhang, G.L. Qiao, F. Zhao, Y. Wang, J. Mol. Liq. 163 (2011) 53-56.

[3] Y. Sun, Q. Yue, B. Gao, Y. Gao, X. Xu, Q. Li, Y. Wang, J. Taiwan Inst. Chem. Eng. 45 (2014) 681-688.

[4] X. Li, S. Chen, X. Fan, X. Quan, F. Tan, Y. Zhang, J. Gao, J. Colloid Interface Sci. http://dx.doi.org/10.1016/j.jcis.2015.01.042 (2015).

[5] E.S.I. El-Shafey, H. Al-Lawati, A.S. Al-Sumri, J. Environ. Sci. 24 (2012) 1579-1586.

[6] C.J. Wang, Z. Li, W.T. Jiang, J.S. Jean, C.C. Liu, J. Hazard. Mater. 183 (2010) 309-314.

[7] Q. Wu, Z. Li, H. Hong, K. Yin, L. Tie, Appl. Clay Sci. 50 (2010) 204-211.

[8] S.A.C. Carabineiro, T. Thavorn-amornsri, M.F.R. Pereira, P. Serp, J.L. Figueiredo, Catal. Today, 186 (2012) 29-34. 
[9] S. Wu, X. Zhao, Y. Li, C. Zhao, Q. Du, J. Sun, Y. Wang, X. Peng, Y. Xia, Z. Wang, L. Xia, Chem. Eng. J. 230 (2013) 389-395.

[10] C. Girardi, J. Greve, M. Lamshoeft, I. Fetzer, A. Miltner, A. Schaeffer, M. Kaestner, J. Hazard. Mater. 198 (2011) 22-30.

[11] J. Tu, Z. Yang, C. Hu, J. Qu, J. Environ. Sci. 26 (2014) 1154-1161.

[12] M. Sui, S. Xing, L. Sheng, S. Huang, H. Guo, J. Hazard. Mater. 227 (2012) 227-236.

[13] X. Van Doorslaer, K. Demeestere, P.M. Heynderickx, H. Van Langenhove, J. Dewulf, Appl. Catal. B 101 (2011) 540-547.

[14] X. Wang, X. Liang, J. Huang, Y.N. Liu, Aiche J. 60 (2014) 2636-2643.

[15] X. Wang, K. Dai, L. Chen, J. Huang, Y.N. Liu, Chem. Eng. J. 242 (2014) 19-26.

[16] Q. Zhou, W. Wang, C. Shuang, M. Wang, Y. Ma, A. Li, Chem. Eng. J. 253 (2014) 190-197.

[17] A.M. Li, Q.X. Zhang, G.C. Zhang, J.L. Chen, Z.H. Fei, F.Q. Liu, Chemosphere, 47 (2002) 981-989.

[18] X. Wang, L. Chen, Y.N. Liu, J. Huang, J. Colloid Interface Sci. 429 (2014) 83-87.

[19] S.A.C. Carabineiro, T. Thavorn-Amornsri, M.F.R. Pereira, J.L. Figueiredo, Water Res. 45 (2011) $4583-4591$

[20] H. Li, D. Zhang, X. Han, B. Xing, Chemosphere, 95 (2014) 150-155.

[21] W.T. Jiang, C.J. Wang, Z. Li, Appl. Clay Sci. 74 (2013) 74-80.

[22] C.J. Wang, Z. Li, W.T. Jiang, Appl. Clay Sci. 53 (2011) 723-728.

[23] Z. Li, H. Hong, L. Liao, C.J. Ackley, L.A. Schulz, R.A. MacDonald, A.L. Miheliche, S.M. Emard, Colloids Surfaces B 88 (2011) 339-344.

[24] W.T. Jiang, P.H. Chang, Y.S. Wang, Y. Tsai, J.S. Jean, Z. Li, K. Krukowski, J. Hazard. Mater. 250 (2013) 362-369.

[25] S. Rakshita, D. Sarkar, E.J. Elzinga, P. Punamiya, R. Datta, J. Hazard. Mater. 246 (2013) 221-226.

[26] C. Gu, K.G. Karthikeyan, Environ. Sci. Technol. 39 (2005) 9166-9173.

[27] J.R. Li, X. Wang, B. Yuan, M.L. Fu, H.J. Cui, Appl. Surf. Sci. 320 (2014) 112-119.

[28] M.J. Manos, M.G. Kanatzidis, Chem. Eur. J. 15 (2009) 4779-4784.

[29] J.R. Li, X. Wang, B. Yuan, M.L. Fu, J. Mol. Liq. 200, Part B (2014) 205-212.

[30] M.J. Manos, N. Ding, M.G. Kanatzidis, Proc. Natl. Acad. Sci. U. S. A., 105 (2008) 3696-3699.

[31] M.J. Manos, V.G. Petkov, M.G. Kanatzidis, Adv. Funct. Mater. 19 (2009) 1087-1092.

[32] J.L. Mertz, Z.H. Fard, C.D. Malliakas, M.J. Manos, M.G. Kanatzidis, Chem. Mater. 25 (2013) 2116-2127. 
1

501 [33] N. Mao, L. Yang, G. Zhao, X. Li, Y. Li, Chem. Eng. J. 200 (2012) 480-490.

502 [34] R.F. Tabor, J. Eastoe, P.J. Dowding, J. Colloid Interface Sci. 346 (2010) 424-428.

503 [35] W.W. Tang, G.M. Zeng, J.L. Gong, Y. Liu, X.Y. Wang, Y.Y. Liu, Z.F. Liu, L. Chen, X.R. Zhang, D.Z. Tu, 504 Chem. Eng. J. 211 (2012) 470-478.

505 [36] G. Bayramoglu, M.Y. Arica, Chem. Eng. J. 139 (2008) 20-28.

506 [37] Z. Li, P.H. Chang, J.S. Jean, W.T. Jiang, C.J. Wang, J. Colloid Interface Sci. 341 (2010) 311-319.

507 [38] L.M. Le Leuch, T.J. Bandosz, Carbon, 45 (2007) 568-578.

508 [39] T. Paul, J. Liu, M.L. Machesky, T.J. Strathmann, J. Colloid Interface Sci. 428 (2014) 63-72.

509 [40] W. Yan, S. Hu, C. Jing, J. Colloid Interface Sci 372 (2012) 141-147.

510 [41] A.J. Carrasquillo, G.L. Bruland, A.A. Mackay, D. Vasudevan, Environ. Sci. Technol. 42 (2008) 7634-7642.

511 [42] H. Zhang, C.H. Huang, Chemosphere, 66 (2007) 1502-1512. 


\section{Tables:}

Table 1. Comparison of adsorption capacity of CIP onto various adsorbents.

\begin{tabular}{lllll}
\hline Adsorbent & $\begin{array}{l}T \\
\left({ }^{\circ} \mathrm{C}\right)\end{array}$ & $\mathrm{pH}$ & $\begin{array}{l}q_{\mathrm{m}} \\
(\mathrm{mg} / \mathrm{g})\end{array}$ & Ref. \\
\hline Modified coal fly ash & 40 & - & 1.547 & {$[2]$} \\
Kaolinite & - & $3.0-4.5$ & 6.3 & {$[23]$} \\
Aluminous oxide & 25 & 7.1 & 13.6 & {$[26]$} \\
Goethite & 22 & 5 & 19.88 & {$[42]$} \\
6\% Graphene & 20 & 6.1 & 66.25 & {$[9]$} \\
oxide/calcium alginate & & & & \\
Chemically prepared & 25 & 6.0 & 104.2 & {$[5]$} \\
carbon (dry) & & & & \\
Carbon xerogel & 25 & 5 & $112 \pm 8$ & {$[8]$} \\
Rectorite & - & $4.0-5.5$ & 135 & {$[22]$} \\
Montmorillonite & - & 3.0 & 400 & {$[7]$} \\
Activated carbon & 25 & 6.0 & 434.8 & {$[3]$} \\
& 10 & 4.0 & 199.6 & Present \\
KMS-1 & 25 & 4.0 & 230.9 & study \\
& 40 & 4.0 & 269.5 & \\
\hline
\end{tabular}




\section{Figure captions:}

Fig. 1. The XRD pattern and molecular structure diagram (inset) of KMS-1.

Fig. 2. Effect of contact time on the adsorption of CIP by KMS-1 (pH=4.0; CIP concentration: 10 and 50 $\mathrm{mg} / \mathrm{L}$; adsorbent dosage: $133 \mathrm{mg} / \mathrm{L}$; temperature: $25^{\circ} \mathrm{C}$ ).

Fig. 3. Effect of initial concentration and temperature on the adsorption of CIP by KMS-1 (pH=4.0; adsorbent dosage: $133 \mathrm{mg} / \mathrm{L}$; contact time: $24 \mathrm{~h}$ ).

Fig. 4. Effect of $\mathrm{pH}$ on the adsorption of CIP by KMS-1 (CIP concentration: $50 \mathrm{mg} / \mathrm{L}$; adsorbent dosage: $133 \mathrm{mg} / \mathrm{L}$; temperature: $25^{\circ} \mathrm{C}$ ).

Fig. 5. XRD patterns of KMS-1 before and after adsorption of CIP at different $\mathrm{pH}$.

Fig. 6. XRD patterns of KMS-1 with various adsorption capacities of CIP at pH 4.0.

Fig. 7. SEM images of KMS-1 before and after adsorption at different $\mathrm{pH}$.

Fig. 8. TEM image of KMS-1 after adsorption of CIP at $\mathrm{pH} 10$.

Fig. 9. EDX of KMS-1 after adsorption of CIP at pH of 10 ((a): EDX on the surface of particle, (b): EDX on the surface of KMS-1).

Fig. 10. FTIR spectra of CIP. $\mathrm{HCl}$ and solid precipitated at different $\mathrm{pH}$.

Fig. 11. FTIR spectra of CIP adsorbed by KMS-1 at different $\mathrm{pH}$.

Fig. 12. Intercalation of cationic CIP with twisted conformation into the interlayer of KMS-1 with a tilted angle of $68^{\circ}$ (a) and $42^{\circ}$ (b). 
1

2

3

4

5

6

7

8

9

10

11

12

13

14

15

16548

17

18549

19

20

21

22

23

24

25

26

27

28

29

30

31

32

33

34

35

36

37

38

39

40

41

42

43

44

45

46

47

48

49

50

51

52

53

54

55

56

57

58

59

60

61

62

63

64

65

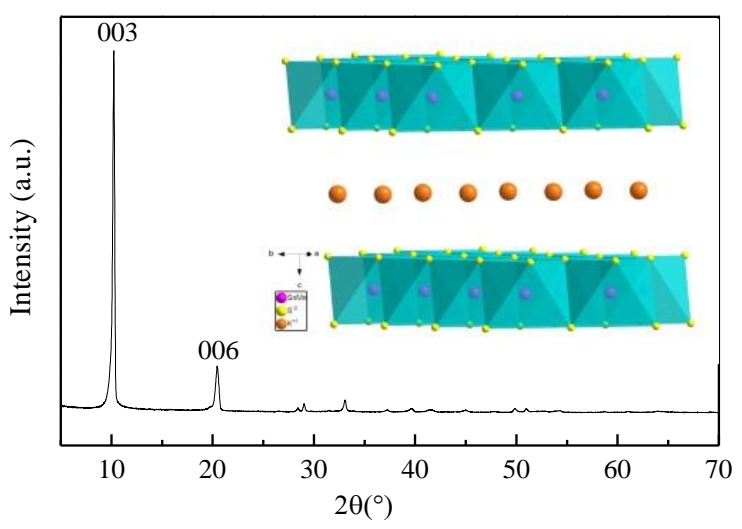

Fig. 1. The XRD pattern and molecular structure diagram (inset) of KMS-1. 


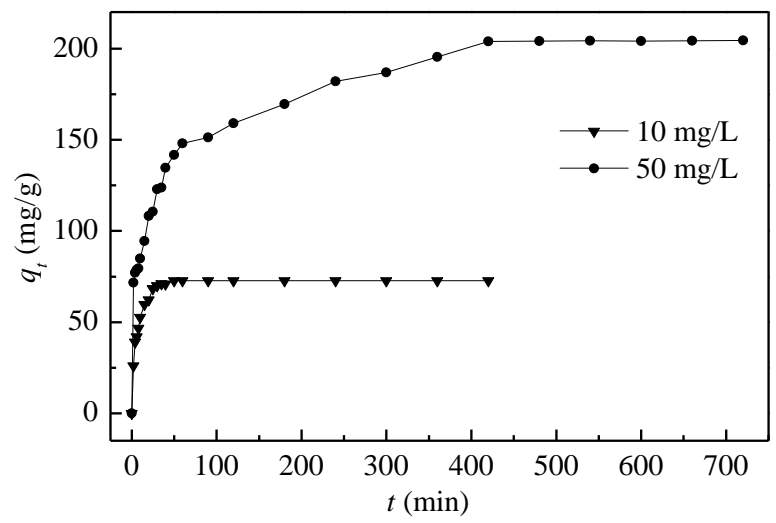

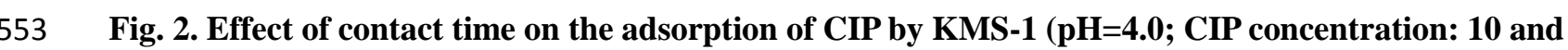
$50 \mathrm{mg} / \mathrm{L}$; adsorbent dosage: $133 \mathrm{mg} / \mathrm{L}$; temperature: $\left.25^{\circ} \mathrm{C}\right)$. 


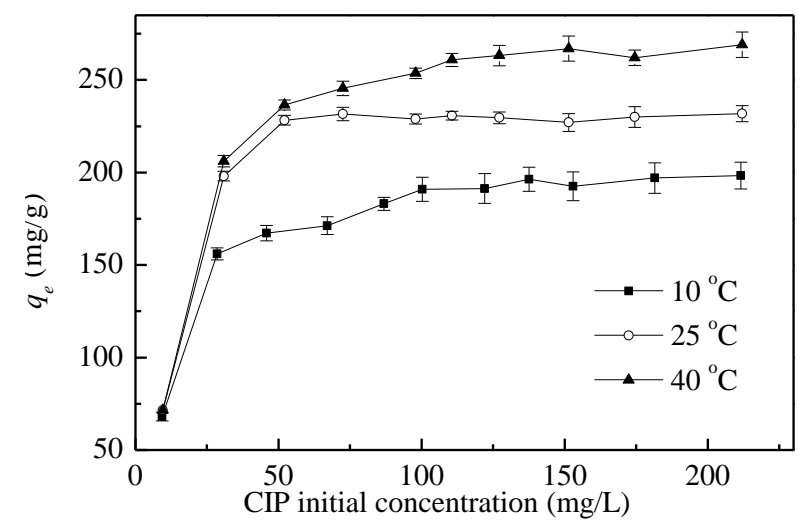

Fig. 3. Effect of initial concentration and temperature on the adsorption of CIP by KMS-1 (pH=4.0; adsorbent dosage: $133 \mathrm{mg} / \mathrm{L}$; contact time: $24 \mathrm{~h}$ ). 
1

2

3

4

5

6

7

8

9

10

11

12

13

14

15

16563

17

18564

19

20

21

22

23

24

25

26

27

28

29

30

31

32

33

34

35

36

37

38

39

40

41

42

43

44

45

46

47

48

49

50

51

52

53

54

55

56

57

58

59

60

61

62

63

64

65

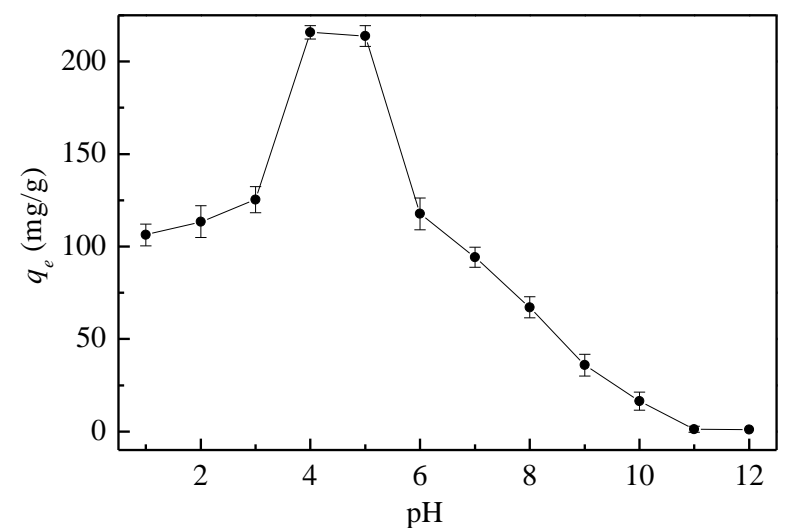

Fig. 4. Effect of pH on the adsorption of CIP by KMS-1 (CIP concentration: $50 \mathrm{mg} / \mathrm{L}$; adsorbent dosage: $133 \mathrm{mg} / \mathrm{L}$; temperature: $25^{\circ} \mathrm{C}$ ). 
1

2

3

4

5

6

7

8

9

10

11

12

13

14

15

16

17

18

19

20

21

22

23

24

25

26

27

28

29

30

31

32

33

34

35

36

37

38

39

40

41568

42

43569

44

45

46

47

48

49

50

51

52

53

54

55

56

57

58

59

60

61

62

63

64

65

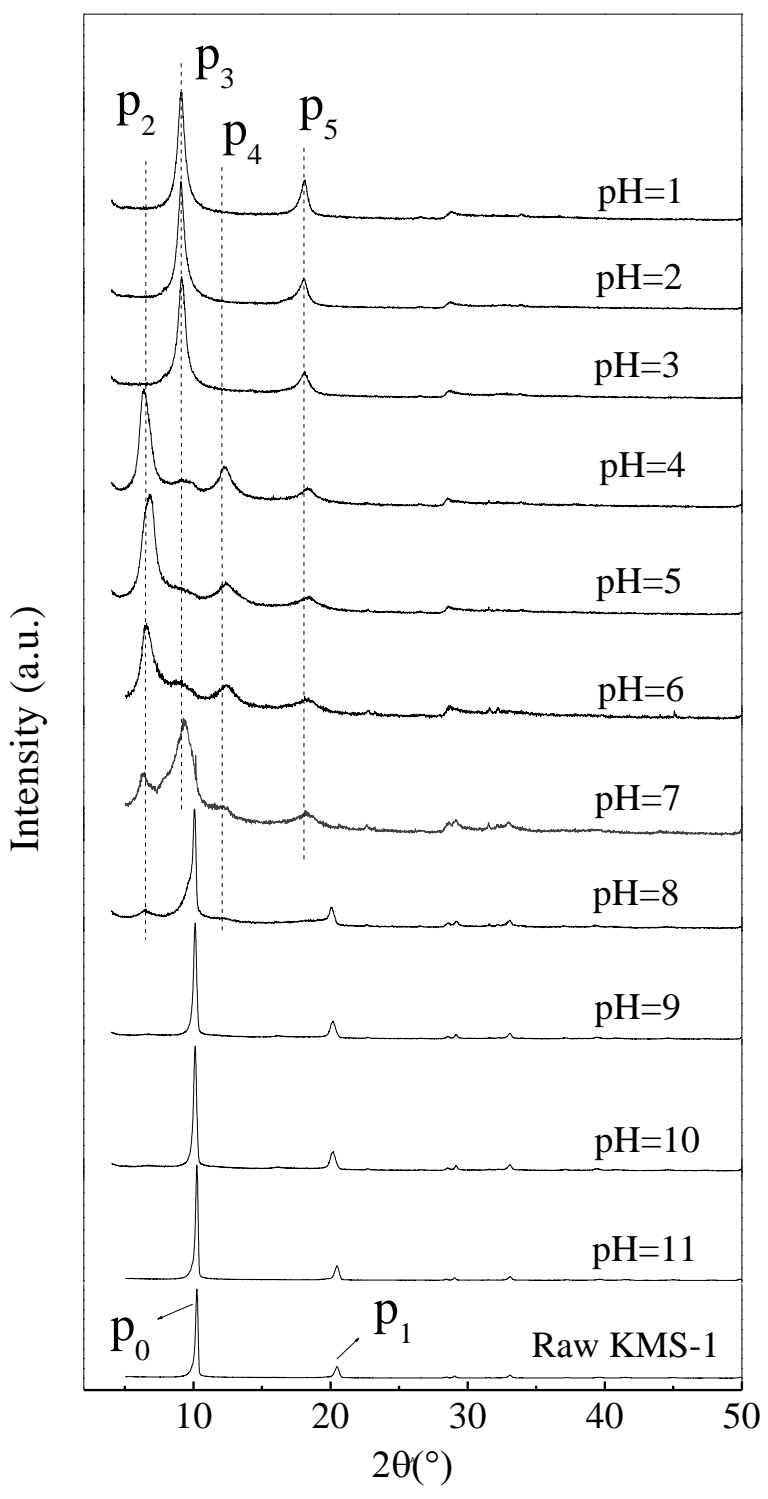

Fig. 5. XRD patterns of KMS-1 before and after adsorption of CIP at different pH. 
1

3

4

5

6

7

8

9

10

11

12

13

14

15

16

17

18

19

20

21

22

23

24571

25

26572

27

28573

29

30

31

32

33

34

35

36

37

38

39

40

41

42

43

44

45

46

47

48

49

50

51

52

53

54

55

56

57

58

59

60

61

62

63

64

65

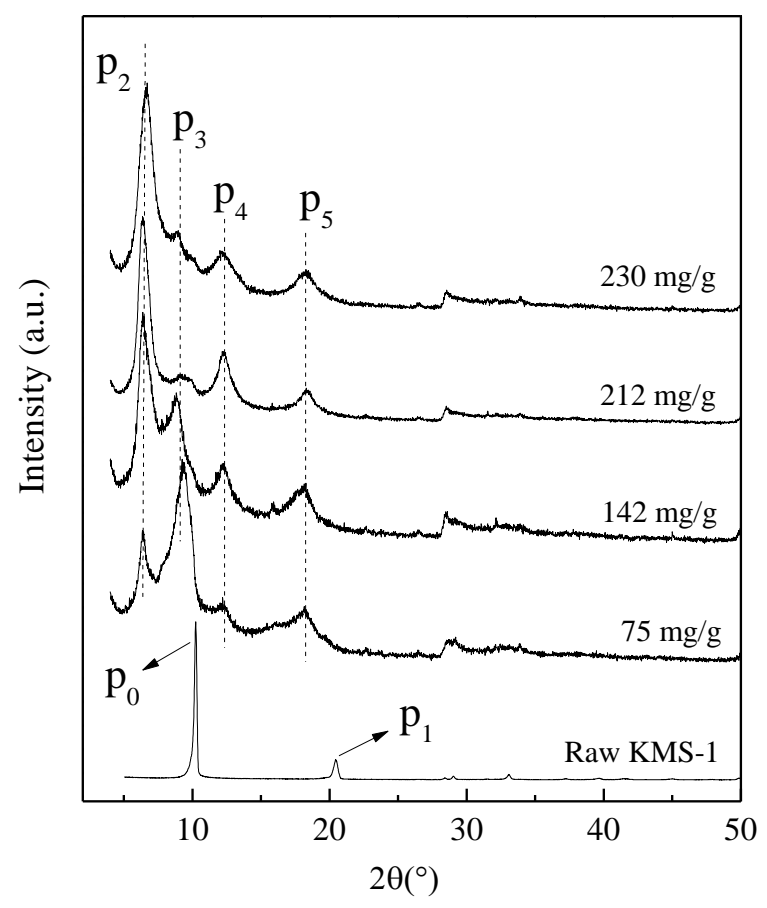

Fig. 6. XRD patterns of KMS-1 with various adsorption capacities of CIP at pH 4.0. 
1

2

3

4

5

6

7

8

9

10

11

12

13

14

15

16

17

18

19

20

21

22

23

24575

25

26576

27

28577

29

30

31

32

33

34

35

36

37

38

39

40

41

42

43

44

45

46

47

48

49

50

51

52

53

54

55

56

57

58

59

60

61

62

63

64

65

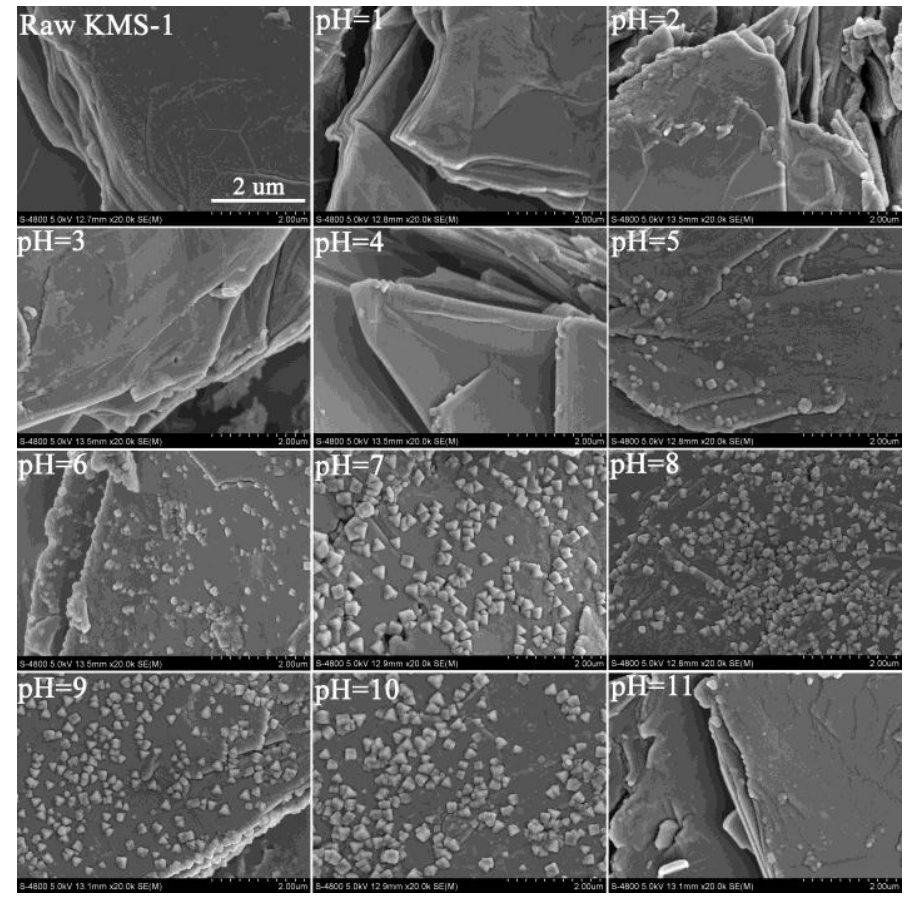

Fig. 7. SEM images of KMS-1 before and after adsorption at different pH. 
1

2

3

4

5

6

7

8

10

11

12

13

14

15

16

17

18

19579

20580

21

22581

23

24

25

26

27

28

29

30

31

32

33

34

35

36

37

38

39

40

41

42

43

44

45

46

47

48

49

50

51

52

53

54

55

56

57

58

59

60

61

62

63

64

65

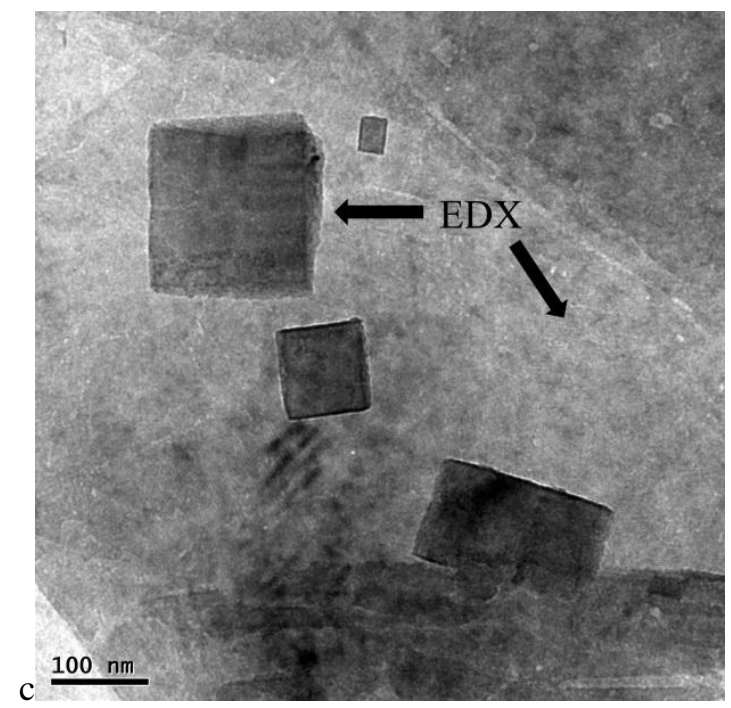

Fig. 8. TEM image of KMS-1 after adsorption of CIP at pH 10. 


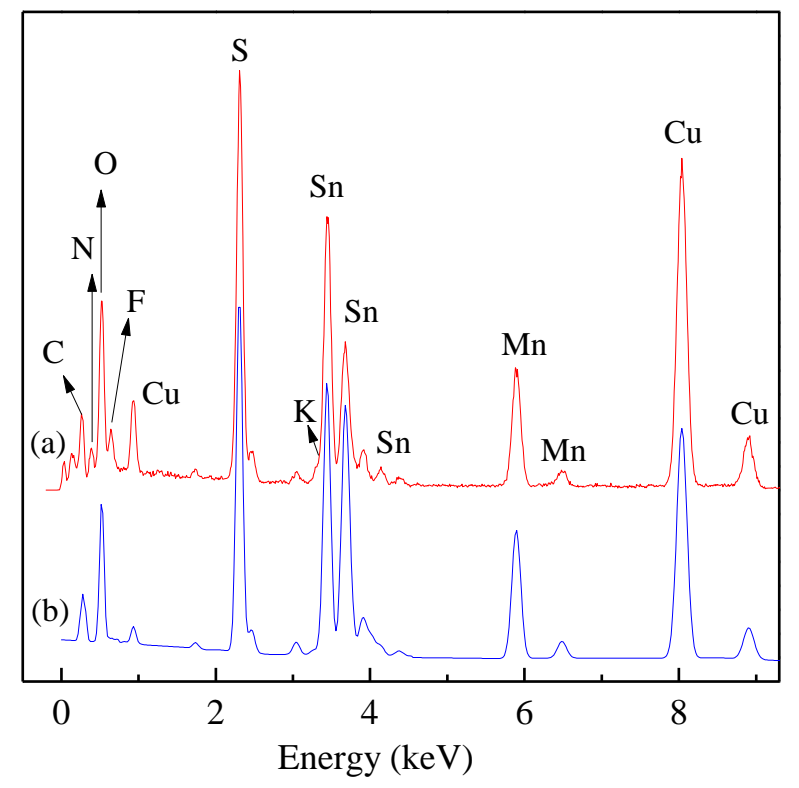

Fig. 9. EDX of KMS-1 after adsorption of CIP at pH of 10 ((a): EDX on the surface of particle, (b): 
1

2

3

4

5

6

7

8

9

10

11

12

13

14

15

16

17588

18

19589

20

21590

22

23

24

25

26

27

28

29

30

31

32

33

34

35

36

37

38

39

40

41

42

43

44

45

46

47

48

49

50

51

52

53

54

55

56

57

58

59

60

61

62

63

64

65

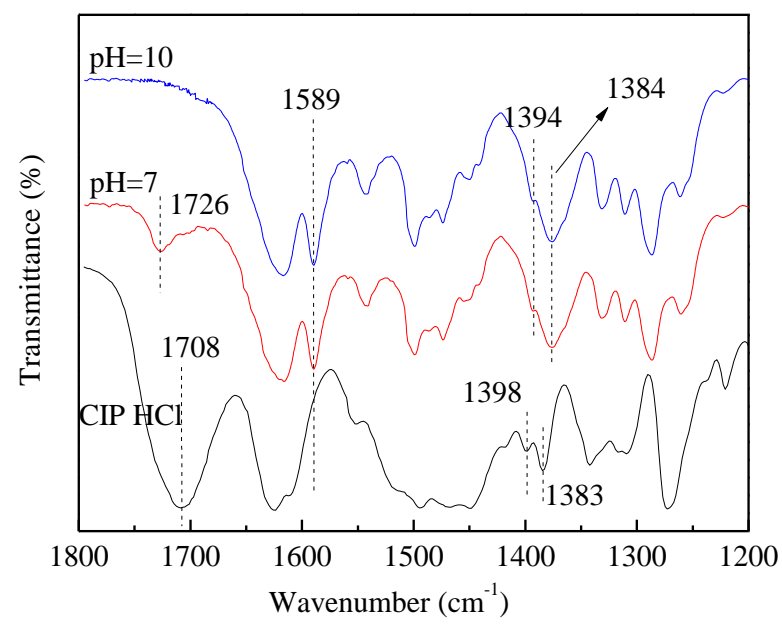

Fig. 10. FTIR spectra of CIP. $\mathrm{HCl}$ and solid precipitated at different $\mathrm{pH}$. 
1

2

3

4

5

7

8

9

10

11

12

13

14

15

16

17592

18

19593

20

21594

22

23

24

25

26

27

28

29

30

31

32

33

34

35

36

37

38

39

40

41

42

43

44

45

46

47

48

49

50

51

52

53

54

55

56

57

58

59

60

61

62

63

64

65

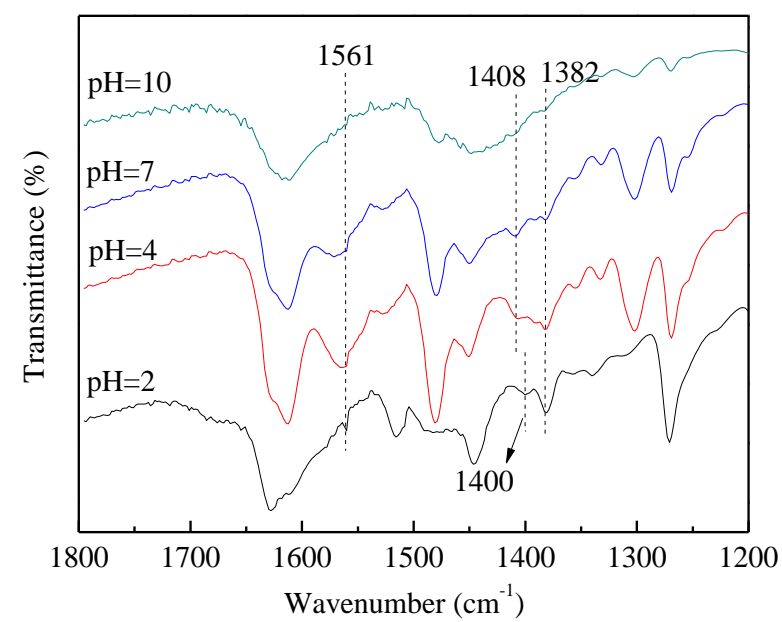

Fig. 11. FTIR spectra of CIP adsorbed by KMS-1 at different pH. 


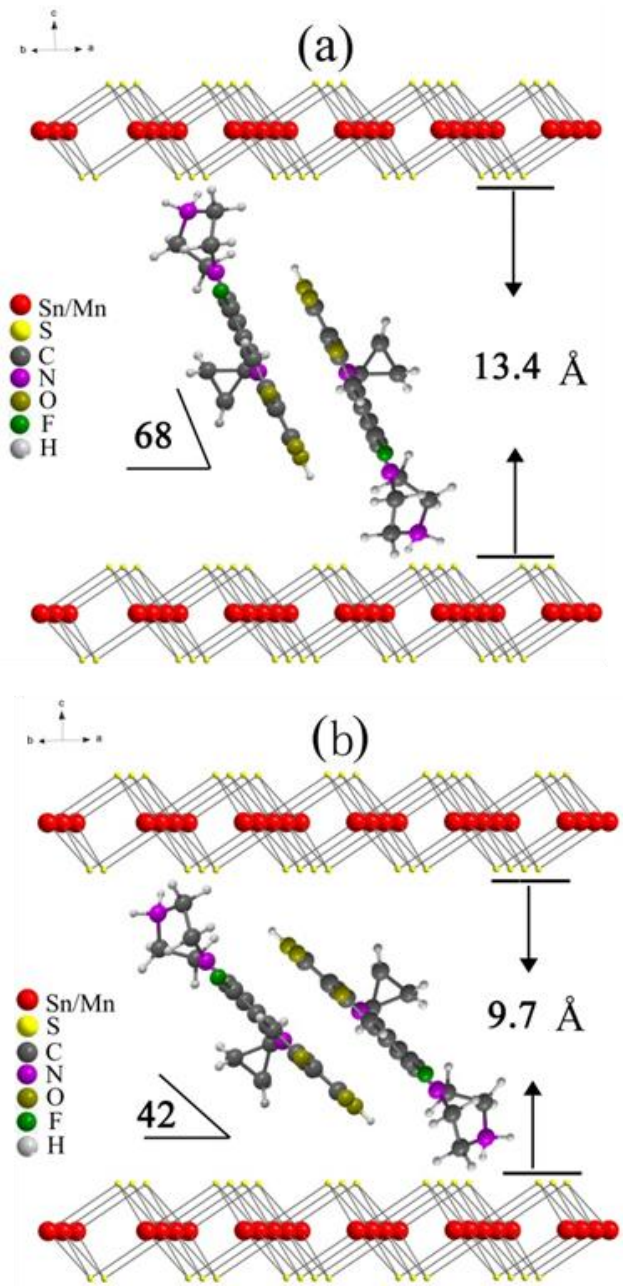

596 Fig. 12. Intercalation of cationic CIP with twisted conformation into the interlayer of KMS-1 with a tilted angle of $68^{\circ}$ (a) and $42^{\circ}(\mathrm{b})$. 